\title{
Variation of geochemical occurrences of rare earth elements in shale during simulated hydrocarbon generation
}

\author{
LIANGBANG MA ${ }^{1,2^{*}}$, QIANGLU CHEN ${ }^{1,2}$, \\ JIE WANG ${ }^{1,2}$, ZHENHENG YANG $^{1,2}$ \\ ${ }^{1}$ Wuxi Research Institute of Petroleum Geology, SINOPEC, \\ Wuxi, Jiangsu 214126, China \\ (*corresponding author:malb.syky@sinopec.com) \\ ${ }^{2}$ SINOPEC Key Laboratory of Petroleum Accumulation \\ Mechanisms, Wuxi, Jiangsu 214126, China
}

Sequential chemical extraction procedure can be applied to research the geochemical occurrences and chemical speciation of trace metals in sediments. Trace metals were partitioned into five fractions: exchangeable (EXC), bound to carbonates (CARB), bound to Fe-Mn oxides (ERO), bound to organic and sulfide matter (OSM), and residual (RES). In this article, we study the variation of geochemical occurrences of rare earth elements(REE) in shale during thermal simulation with the hydrocarbon generation and expulsion simulation experiment instrument ${ }^{[1]}$. The shale sample(TOC\% is $9.8 \%$ ) was heated at $1{ }^{\circ} \mathrm{C} / \mathrm{min}$ and then held at the final temperature $\left(325,360,420,480,550^{\circ} \mathrm{C}\right)$ for $24 \mathrm{~h}$. The shale and residue samples were processed by sequential chemical extraction.

Analysis of datas shows the recovery rate of sum of five fraction reaches $95.3 \%$ to $104.9 \%$. It means there is no loss and contamination in the sequential chemical extraction process. REE are mainly in CARB, ERO and RES fractions and is lack of the contents in EXC and OSM fractions. The total content and occurrence of REE in the five simulated samples residue do not change obviously compared with the original sample. This also shows that REE in the shale sample did not migrate almost with hydrocarbon expulsion. But REE content change in some fraction with the increased thermal evolution. The REE content in EXC is very low and the variation trend is negligible. The REE content in CARB increased with the increased thermal evolution and reach the peak at $360^{\circ} \mathrm{C}$, then decreased; The REE content in ERO and OSM increased gradually with the increased thermal evolution, this shows the organic matter pyrolysis had little effect on the migration of REE because they exist as the stable organic complexes. The thermal maturation of organic matter generates mainly the pyrolysis and have little influence on REE. The REE content in RES is the opposite variation trend to the CARB, this shows aluminosilicate bound fraction are more inclined to enrich REE.

[1]Li ZM et al. (2011) Petroleum Geology \& Experiment, 33(5): 447-451. 